\title{
REMINERALIZATION POTENTIAL OF LACTOSE- FREE AND PLANT BASED MILK ON ENAMEL SURFACE OF HUMAN TEETH SUBJECTED TO ENERGY DRINKS
}

\author{
Mona El Deeb* and Rehab A. Abdel Moneim**
}

\begin{abstract}
Objective: Multiple etiological factors contribute to the process of erosion and destruction of enamel. Among which, carbonated soft beverages and energy drinks are the most aggressive extrinsic causes. The consumption of milk whether bovine or plant based highly contributes to the remineralization process.

Design: Thirty five freshly extracted sound human maxillary first premolars were used and randomly divided into the following groups; Group I (Control group): included 5 teeth immersed in distilled water. Group II (Power Horse group): 15 teeth were immersed in $330 \mathrm{ml}$ of the drink. Group III (Cornelius group): 15 teeth were immersed in 330ml of the energy drink. After 10 days, the teeth were further randomly divided as follows (5 teeth each); Group IV (Power Horse +Lactose free milk), Group V (Power Horse +Almond milk), Group VI (Cornelius +Lactose free milk) and Group VII (Cornelius +Almond milk). Teeth of groups IV-VII were placed in both types of milk for 5 days where the milk was changed every 2 hrs. The remaining teeth from groups II and III ( 5 teeth each) were kept in distilled water. At the end of the experimental period, the teeth were prepared for SEM examination, EDX and statistical analyses.
\end{abstract}

Results: SEM examination showed that surface erosion was more aggressive in Power Horse group (II) when compared to Cornelius group (III). Furthermore, the results revealed better remineralizing effect in groups IV and VI (lactose free treated) rather than those treated with almond milk (groups V and VII). EDX results presented statistically significant decrease in Ca and $\mathrm{P}$ wt $\%$ in group II compared to group III. Statistically significant increase in Ca and $\mathrm{P}$ wt \% in group IV in relation to group V and similarly, significant increase in group VI compared to group VII were also detected.

Conclusion: Energy drinks produce erosive defects of varying intensity on the enamel surface of human teeth. The intake of remineralizing agents; such as milk, immediately following every meal containing acidic diet is mandatory to reverse the demineralization process.

KEYWORDS: enamel, erosion, energy drinks, lactose-free milk, almond milk.

* Associate Professor, Oral Biology Department, Faculty of Dentistry, Future University in Egypt

** Associate Professor, Oral Biology Department, Faculty of Dentistry, Cairo University and Future University in Egypt 


\section{INTRODUCTION}

Changing lifestyle and daily pattern of diet have a chief role in the widespread rise of dental erosion. Dental erosion is caused by repeated contact of the erosive acidic agent and surface of the tooth ${ }^{(1)}$. This results in dental hard tissue loss and thinning which is not associated with microorganisms ${ }^{(2)}$.

Endogenous factors causing dental erosion involves gastric reflux of the stomach leading to tooth damage with acidic contact. On the other hand, exogenous factors results from regular consumption of acidic diet and beverages or from frequent intake of acidic drugs ${ }^{(3)}$. Unrestricted ingestion of carbonated soft beverages and high energy drinks (EDs) are among the most aggressive extrinsic causes of dental erosion ${ }^{(4)}$.

Recently, consumption of sports and EDs is gaining more popularity worldwide over usual carbonated soft drinks ${ }^{(5)}$. EDs are carbonated, non-alcoholic drinks available in the form of cans or bottles mostly consumed by youths, undergraduates and desk workers ${ }^{(6)}$. They have been found to improve physical resistance and mental performance, enhance concentration and alertness ${ }^{(7)}$. They also increase the rate of metabolism during various sports and activities ${ }^{(8)}$. These beverages are composed of caffeine, carbohydrates, proteins, amino acids, vitamin B, minerals, and acids as citric, phosphoric and malic acids ${ }^{(\mathbf{8}, 9)}$. The existence of acids lowers the $\mathrm{pH}$ of these drinks making them potentially erosive. Thus high consumers become more susceptible to serious dental problems and high rates of dental erosion $^{(\mathbf{1 0})}$.

Although excessive use of acidic drinks increases the risk of enamel demineralization, this effect could be reversed when remineralizing agents exist (11). Remineralization involves diffusion of calcium and phosphate ions within the defect to regain the tooth subsurface ${ }^{(12)}$. These minerals are normally found in bovine milk and its products ${ }^{(13)}$, together with other milk based bioactive agents which release some components improving the remineralization process ${ }^{(\mathbf{1 2})}$.

Lactose intolerance is a major worldwide problem. Therefore, lactose-free dairy milk is targeted to individuals who have lactase enzyme deficiency which breaks down milk sugar, lactose, into galactose and glucose ${ }^{(14)}$.

Unfortunately, allergy to cow milk, lactose intolerance, hypercholesterolemia and calorie issues restrict the use of dairy milk for certain group of population ${ }^{(15-17)}$. Thus, there is a fast growing shift to plant based alternative milk products as being lactose free, cholesterol free and having low calories ${ }^{(18)}$. Among these existing alternatives are almond, soy, oat, rice and coconut milk based beverages ${ }^{(19)}$. Compared to other plant-based milk alternatives, almond milk contains significant high amount of calcium, phosphorus, potassium, magnesium, selenium, iron, zinc and vitamin $\mathrm{E}^{(\mathbf{2 0 , 1 6})}$. Recently, sales of almond milk have surpassed all other available dairy alternatives ${ }^{(21)}$.

It was reported that ingestion of milk following an erosive challenge may exhibit reparative influence on enamel remineralization ${ }^{(22)}$. Yet, limited information regarding the remineralizing effect of milk and its products is available ${ }^{(\mathbf{1 2})}$.

Therefore, the aim of this study was to compare the erosive effect of some commercially available EDs, and to reveal the possible remineralizing effect of lactose-free dairy milk and almond plant basedmilk on human maxillary first premolars.

\section{MATERIALS AND METHODS}

This study was carried on thirty five sound human maxillary first premolars freshly extracted for orthodontic reasons. The teeth were cleaned gently from residual debris, washed thoroughly under running water and stored in distilled water. The premolars were examined under stereomicroscope to ensure absence of caries, calculus or any defects particularly on the buccal surface. 


\section{* MATERIALS}

I- Energy Drinks (EDs); two types were used in the study

a) Power Horse - ED

- Ingredients: carbonated water, sucrose, glucose, citric acid, taurine, glucoronolactone $(240 \mathrm{mg} / 100 \mathrm{ml})$, artificial flavor (Tutti-Frutti), caffeine $(32 \mathrm{mg} / 100 \mathrm{ml})$, colour (caramel), inositol (20mg/ 100ml), niacin, pantothenic acid, vitamins B6, B12 and riboflavin.

- Manufactured by S. Spitz GmbH, Attnang Puchheim, Austria.

- Purchased from market as $250 \mathrm{ml}$ disposable cans.

b) Cornelius Organic ED

- Ingredients: water, biosugar, carbon dioxide, citric acid, taurine $(0.4 \%)$, acidity regulator sodium citrate, caffeine $(0.03 \%)$, colour sulphite ammonia caramel, riboflavins, niacin, pantothenic acid, vitamins B6 and B12.

- Manufactured by AM BEVERAGES GLOBAL TRADING FZC- Poland.

- Purchased from market as $250 \mathrm{ml}$ disposable cans.

N.B.: For each ED; the $\mathrm{pH}$ and titratable acidity (TA) were measured at Faculty of Pharmacy, Future University in Egypt.

\section{pH measurement}

For $\mathrm{pH}$ measurement; a potentiometer ( $\mathrm{pH}-$ Meter E520, Switzerland) was used where an electrode was connected and calibrated at $\mathrm{pH} 7$ and $\mathrm{pH} 4$ with a standard solution. The beverages to be tested were maintained at ambient temperature $\left(\sim 25^{\circ} \mathrm{C}\right){ }^{(10)}$.

\section{Measurement of titratable acidity (TA)}

For each beverage used; $100 \mathrm{ml}$ was titrated using $1 \mathrm{M} \mathrm{NaOH}$ which was added in $0.2 \mathrm{ml}$ increments until the $\mathrm{pH}$ reached 7. After each increment $(0.2 \mathrm{ml})$ of $\mathrm{NaOH}$, a non heating magnetic stirrer was used till a stable $\mathrm{pH}$ reading was reached. This procedure was done in order to measure the total TA and the amount of $\mathrm{NaOH}$ required to raise the $\mathrm{pH}$ to $7^{(2)}$.

II- Milk; two different types of milk were assessed in this work

a) Juhayna Lactose Free Full Cream Cow's Milk

- Ingredients: UHT Full Cream Cow's Milk, lactase enzyme (non animal origin), 3\% fat, $8.25 \%$ SNF, lactose $(<0.1 \%)$, fat, protein, carbohydrates, calcium, phosphorous, vitamins B1 and B2. Free from milk powder, preservatives and any other additives.

- Manufactured by The Egyptian Company For Food Industries (Egyfood), $6^{\text {th }}$ October City, Egypt.

- Purchased from market as one liter disposable packs.

b) Almond Breeze Almond Milk

- Ingredients: Almond milk, (filtered water, almonds), cane sugar, calcium carbonate, sea salt, potassium citrate, sunflower lecithin, geltan gum, vitamin A, palmitate, vitamin D2, D-Alpha-Tocopherol (natural vitamin E), fat $4 \%$, sodium, potassium, carbohydrates, calcium, phosphorous, riboflavin, magnesium.

- Manufactured by Blue Diamond Growers, Sacramento, USA.

- Purchased from market as one liter disposable packs.

\footnotetext{
* Measured $\mathrm{pH}$ and TA of Power Horse ED were 2.52 and 26.8 respectively.

** Measured pH and TA of Cornelius ED were 2.75 and 19.4 respectively.
} 


\section{* Experimental Design}

The teeth were divided into the following groups;

Group I (Control group): included 5 teeth immersed in distilled water throughout the experimental period.

Group II (Power Horse group): 15 teeth were immersed in a container filled with $330 \mathrm{ml}$ of the drink.

Group III (Cornelius group): This group included 15 teeth immersed in a container filled with $330 \mathrm{ml}$ of the energy drink.

**For groups II and III; the beverages were changed daily (every 24 hrs) for 10 days ${ }^{(9)}$. After 10 days, the teeth were washed for seconds under running water, left to dry and then were randomly divided as follows;

Group IV (Power Horse +Lactose free milk): 5 teeth from group II were placed in $125 \mathrm{ml}$ of lactose free milk.

Group V (Power Horse + Almond milk): another 5 teeth from group II were placed in $125 \mathrm{ml}$ almond milk.

Group VI (Cornelius +Lactose free milk): This group included 5 teeth from group III were placed in $125 \mathrm{ml}$ lactose free milk.

Group VII (Cornelius +Almond milk): another 5 teeth from group III were immersed in $125 \mathrm{ml}$ almond milk.

**Teeth of groups IV-VII were placed in both types of milk for 5 days where the milk was changed every 2 hrs ${ }^{(23)}$. The remaining teeth from groups II and III (5 teeth each) were kept in separate beakers filled with distilled water.

\section{Scanning electron microscopic examination:}

At the end of the experimental period (15 days), teeth of all groups were washed under running water and left to dry in open air. The cervical third of the buccal surfaces of the teeth was studied using scanning electron microscope (SEM) model Quanta 250 FEG (Field Emission Gun) attached with EDX Unit (Energy Dispersive X-ray Analyses) and accelerating voltage $30 \mathrm{~K}$.V., magnification $14 \mathrm{x}$ up to 1000000 and resolution for Gun.1n. (FEI Company, Netherlands). This was carried at the Scanning Electron Microscope Unit, Egyptian Mineral Resources Authority "Egyptian Geological Survey" (EMRA), Ministry of Petroleum.

\section{Statistical analysis:}

Data were coded and entered using the statistical package SPSS version 22. Data was summarized using mean and standard deviation. Comparisons between groups were done using analysis of variance (ANOVA) with multiple comparisons post hoc test when comparing more than 2 groups. Correlations between quantitative variables were done using Pearson correlation coefficient ${ }^{(24)}$.

\section{RESULTS}

\section{I- Scanning electron microscope (SEM)}

\section{Group I (Control group)}

Scanning electron microscopic (SEM) examination of enamel of the cervical third of the buccal surface of control group specimens nearly presented the same normal surface features. Numerous perikymata, rod ends with variable depth as well as areas of rodless or structurless enamel were evident. Perikymata which represented the external manifestation of the brown striae of Retzius appeared as slightly undulating parallel grooves; some of which were pronounced depressions; others were faint and poorly developed. Rod ends were evident as surface concavities inbetween the perikymata. Moreover, fine grooves were detected on the enamel surface more or less at right angle to the perikymata. Also, very few depressions or pits were normally seen on the enamel surface. (Fig. 1) 


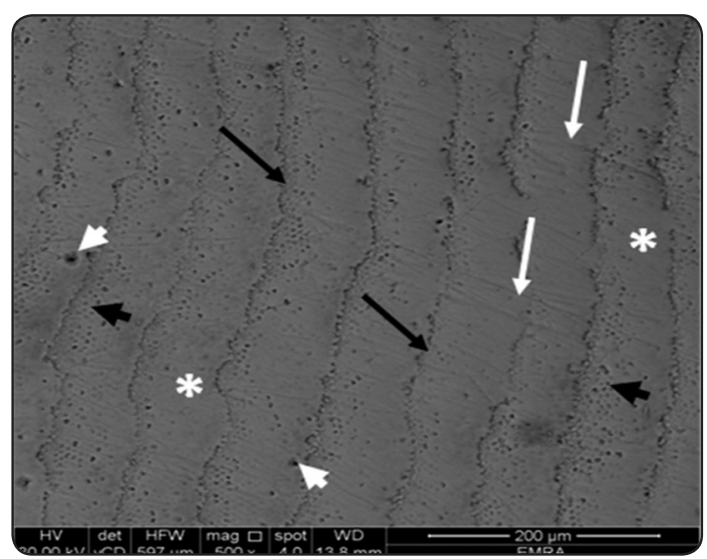

Fig. (1) Scanning electron micrograph of group I (control group) showing; numerous perikymata (black arrows), rod ends (black arrow heads), areas of rodless or structurless enamel (asterisks), fine grooves (white arrows), and few depressions or pits (white arrow heads) (Orig. Mag. x 500)

\section{Group II (Power Horse group)}

On examination of the enamel surface of group II specimens; the cervical third revealed various surface defects. These defects included dissolution of the enamel surface, cracking, erosion and porosity. In comparison to the control group; areas of rodless enamel were increased in relation to the few scattered rod ends which were still detected denoting surface dissolution. Obvious cracks ranging from shallow, intermediate to deep ones were seen along the entire enamel surface. Morphologic surface defects also included pitting; few crater like depressions and irregularities as well as granular deposits. Unlike the control group, only remnants of the perikymata were evident. (Fig. 2)

\section{Group III (Cornelius group)}

Scanning electron microscopic examination of these group specimens showed certain variations; in a way the surface texture was maintained compared to the control group and even the morphologic defects detected were considered of less intensity regarding group II. In all specimens, the pattern of perikymata was well defined along the entire cervical third. However, some showed obviously deep cracks while others presented shallow grooves.

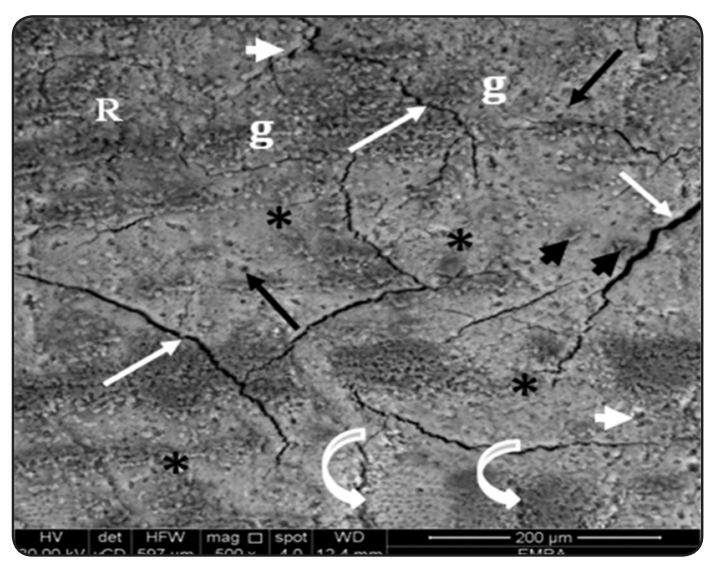

Fig. (2) Scanning electron micrograph of group II (Power Horse group) showing; obvious cracks ranging from shallow, intermediate to deep ones (white arrows), increased areas of rodless enamel (asterisks), few scattered rod ends (black arrows), pitting (white arrow heads), few crater like erosions (black arrow heads), surface irregularities (R), granular deposits (g) and remnants of perikymata (curved arrows) (Orig. Mag. x 500)

Minor pitting with very few granular deposits was also detected. The rod ends appeared shallow to the extent that they were not obvious in some specimens except along the periphery of perikymata. (Figs. 3a \& 3b)

\section{Group IV (Power Horse + Lactose free milk)}

Scanning electron microscopic examination of group IV specimens revealed massive calcific deposits nearly filling all cracks and surface defects that resulted from the power horse energy drink. The majority of the deposits exhibited needle like appearance which were more or less arranged regularly parallel to each other; others assumed granular pattern. However, areas of structurless enamel could be seen with minute cracks. On higher magnification, examination of the enamel surface showed highly organized rod ends with evident key hole appearance or fish scale arrangement. Some of the calcific deposits were seen obliterating the enamel rods either partially or even completely. (Figs. 4a \& 4b)

\section{Group V (Power Horse +Almond milk)}

Unlike the previous group; the enamel surface of this group's specimens still presented certain 
morphologic defects ranging from surface pitting to cracks of variable intensity. Moreover, areas of structurless enamel could be detected with only traces of the rod ends on higher magnification. Evidence of calcific deposits was marked; either granular or feather like in appearance scattered on the surface or irregularly arranged needle like deposits in an attempt to obliterate the cracks. The amount of calcific deposits was relatively less than that observed in group IV. (Figs. 5a \& 5b)

\section{Group VI (Cornelius + Lactose free milk)}

Signs of mineralization were evident on the cervical third of the buccal surface of the specimens when examined under the SEM. Yet, apparently the degree of mineralization was far less in intensity and distribution when compared to groups IV and V. The calcific deposits which were haphazardly distributed assumed various patterns; granular or feather like and needle shaped filling most of the tiny surface

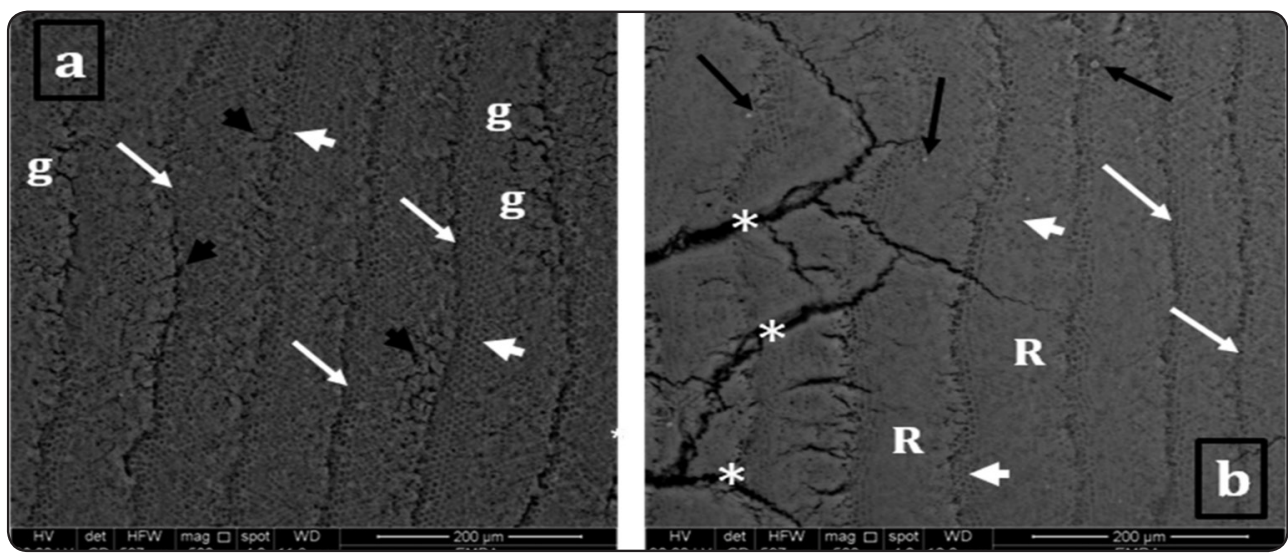

Fig. (3) (a) Scanning electron micrograph of group III (Cornelius group) showing; well defined perikymata (white arrows), shallow rod ends along the periphery of perikymata (white arrow heads), shallow grooves ( $\mathrm{g}$ ) and minor pitting (black arrow heads) (Orig. Mag. x 500). (b) Another scanning electron micrograph of group III (Cornelius group) showing; well defined perikymata (white arrows), deep cracks (asterisks), shallow rod ends (white arrow heads), rodless areas (R) and very few granular deposits (black arrows) (Orig. Mag. x 500)

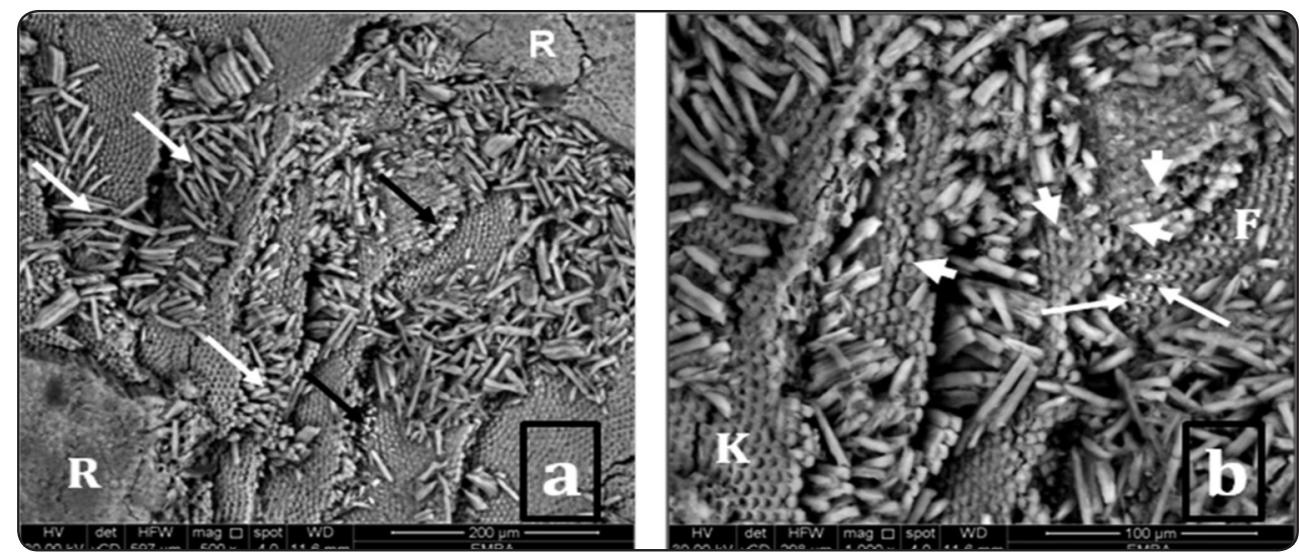

Fig. (4) Scanning electron micrograph of group IV (Power Horse +Lactose free milk) showing; massive calcific deposits nearly filling all cracks and surface defects. (a) Needle like calcific deposits parallel to each other (white arrows), few granular deposits (black arrows) and areas of structurless enamel with minute cracks (R) (Orig. Mag. x 500). (b) Higher magnification of the previous micrograph showing; highly organized rod ends with key hole (K) or fish scale (F) appearance, and calcific deposits obliterating the enamel rods either partially (white arrows) or completely (white arrow heads) (Orig. Mag. x 1000) 
defects previously stated in group III. Furthermore, the enamel surface revealed regularly arranged perikymata with evidence of rod ends assuming fish scale pattern. On higher magnification, needle like deposits were seen obliterating few rod ends. (Figs. 6a\& 6b)

\section{Group VII (Cornelius +Almond milk)}

On SEM examination, the least degree of mineralization was detected on the enamel surface of the specimens of this group in comparison to the previous experimental groups (IV, V \& VI). Still the enamel surface presented tiny grooves in addition to the detected perikymata, rods and minute areas of rodless enamel. On higher magnification, the mineralization pattern exhibited a granular appearance with various sizes ranging from minute to large granules; others assumed feather shape and few appeared needle like. Granular deposits were seen obliterating some of the rod ends. Moreover, calcifications could be detected within the deepened perikymata as well as along the periphery of some rod ends. (Figs. 7a\& 7b)
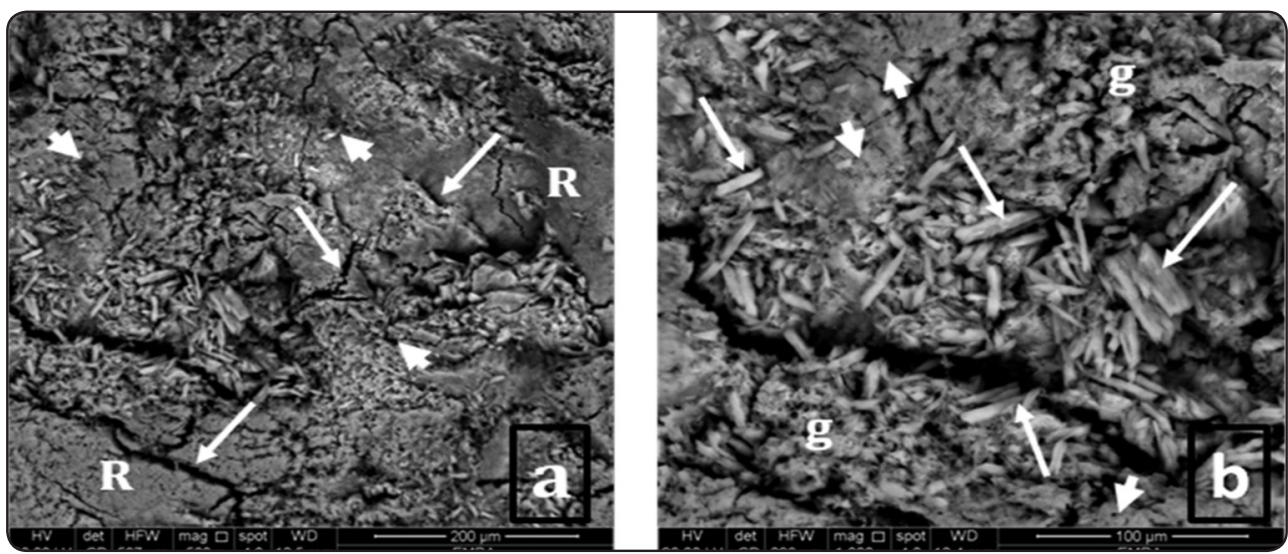

Fig. (5) Scanning electron micrograph of group V (Power Horse +Almond milk) showing; irregularly distributed calcifications.(a) Surface pitting (white arrow heads), cracks of variable intensity (white arrows) and areas of structurless enamel (R) (Orig. Mag. x 500) (b) Higher magnification of the previous micrograph showing; traces of rod ends (white arrow heads), granular or feather like calcific deposits (g) and irregularly arranged needle like (white arrows) (Orig. Mag. x 1000)

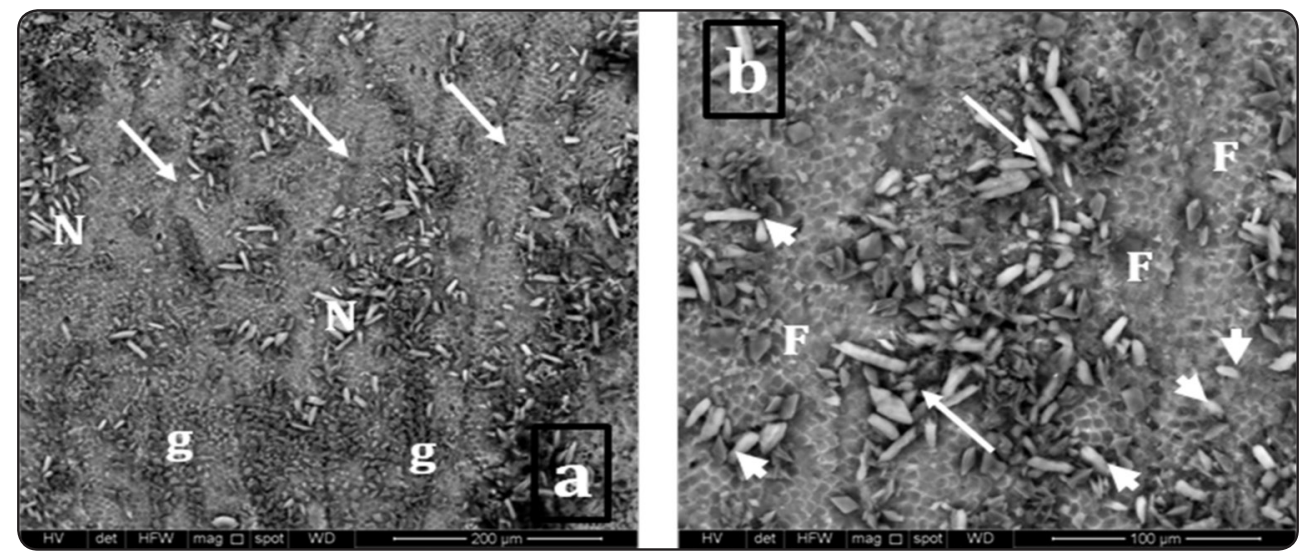

Fig. (6) Scanning electron micrograph of group VI (Cornelius +Lactose free milk) showing; few scattered calcifications. (a) Regularly arranged perikymata (white arrows), calcific deposits; granular or feather like (g) and needle shaped (N) (Orig. Mag. x 500). (b) Higher magnification of the previous micrograph showing; rod ends assuming fish scale pattern (F), calcifications filling most of the tiny surface defects (white arrows) and needle like deposits obliterating few rod ends (white arrow heads) (Orig. Mag. x 1000) 


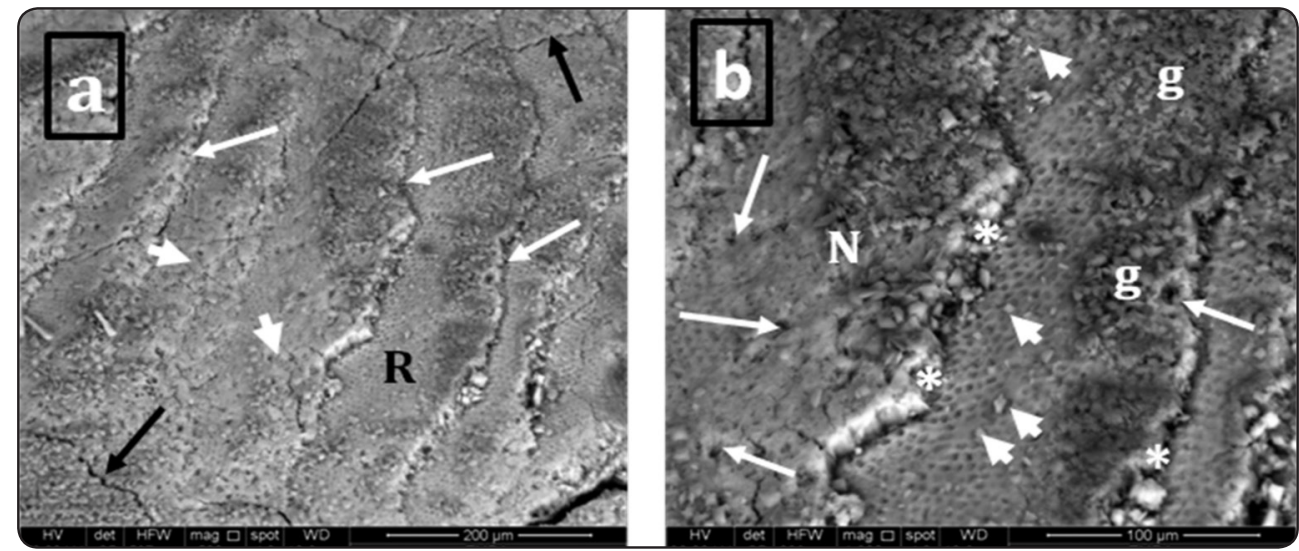

Fig. (7) Scanning electron micrograph of group VII (Cornelius +Almond milk) showing; the least degree of mineralization. (a) Tiny grooves (black arrows), perikymata (white arrows), rod ends (white arrow heads) and minute areas of rodless enamel (R) (Orig. Mag. x 500). (b) Higher magnification of the previous micrograph showing; granular or feather shaped mineralization pattern $(\mathrm{g})$, few needle like deposits $(\mathrm{N})$, granular deposits obliterating some of the rod ends (white arrow heads), calcifications within the deepened perikymata (asterisks) as well as along the periphery of some rod ends (white arrows) (Orig. Mag. x 1000)

\section{II- Chemical Profile Results}

The elements detected by energy dispersive $\mathrm{x}$-ray analysis (EDX) in the cervical third of the enamel of the buccal surfaces of the specimens were calcium $(\mathrm{Ca})$, phosphorus $(\mathrm{P})$, carbon $(\mathrm{C})$ and oxygen $(\mathrm{O})$. These elements differed in weight percent (wt \%) from one specimen to another (Fig.8).

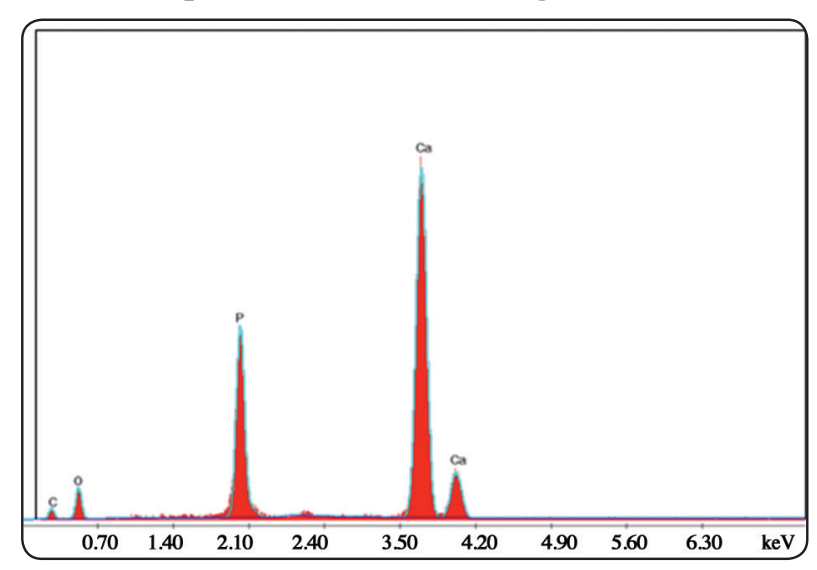

Fig. (8) EDX chart obtained from the cervical third of the enamel of the buccal surfaces.

\section{III- Statistical Results}

Statistics was utilized for the analysis of EDX results of $\mathrm{Ca}$ and $\mathrm{P}$ wt \%. Data were represented as mean and standard deviation (SD) values.

\section{Comparisons between groups:}

\section{a) Calcium weight percent (Ca wt \%)}

Statistical analysis revealed significant decrease in $\mathrm{Ca}$ wt $\%$ in groups (II-VII) compared to group I ( $p$ value $=0.00$ for groups II, III, IV, V, VII and 0.002 for group $V I)$. On the other hand, significant increase in $\mathrm{Ca}$ wt \% was detected in group III compared to group II ( $p$ value $=0.016$ ) as well as in groups IV and V compared to group II ( $p$ value $=0.00)$. In addition, $\mathrm{Ca} w \mathrm{wt} \%$ showed statistical significant increase in groups VI and VII compared to group III ( $p$ value $=0.00$ ). According to the statistical analysis, there was significant decrease in Ca wt \% in group V compared to group IV ( $p$ value $=0.009)$ and in group VII compared to group VI $(p$ value $=0.001)$ (Table 1and figs. 9\&10).

\section{b) Phosphorus weight percent (P wt \%)}

Similar to the statistical analysis of $\mathrm{Ca}$ wt \%; significant decrease in $\mathrm{P}$ wt $\%$ was detected in groups (II-VII) when compared to group I ( $p$ value $=0.00)$. However, there was statistical significant increase in group III compared to group II ( $p$ value $=0.00)$ and in groups IV-V in relation to group II ( $p$ value $=0.00)$. Also, Groups VI and VII revealed 
Table (1) Showing mean and standard deviation values of Ca wt \% for all groups (I-VII)

\begin{tabular}{|l|c|c|c|c|c|}
\hline \multicolumn{1}{|c|}{ Group } & Mean & Standard Deviation & Minimum & Maximum & P value \\
\hline Group I & 51.59 & 0.23 & 51.36 & 51.82 & 41.99 \\
\hline Group II & 41.09 & 0.9 & 40.19 & 42.82 & $<0.001$ \\
\hline Group III & 42.46 & 0.36 & 42.10 & 46.11 & 44.89 \\
\hline Group IV & 45.97 & 0.14 & 45.83 & 49.91 & 48.11 \\
\hline Group V & 44.5 & 0.39 & 44.11 & 49.78 & \\
\hline Group VI & 49.84 & 0.06 & 47.72 & & \\
\hline Group VII & 47.91 & 0.19 & & & \\
\hline
\end{tabular}

statistical significant increase in $\mathrm{P}$ wt $\%$ when compared to group III ( $p$ value $=0.00$ ). On the other hand, there was significant decrease in $\mathrm{P}$ wt $\%$ in

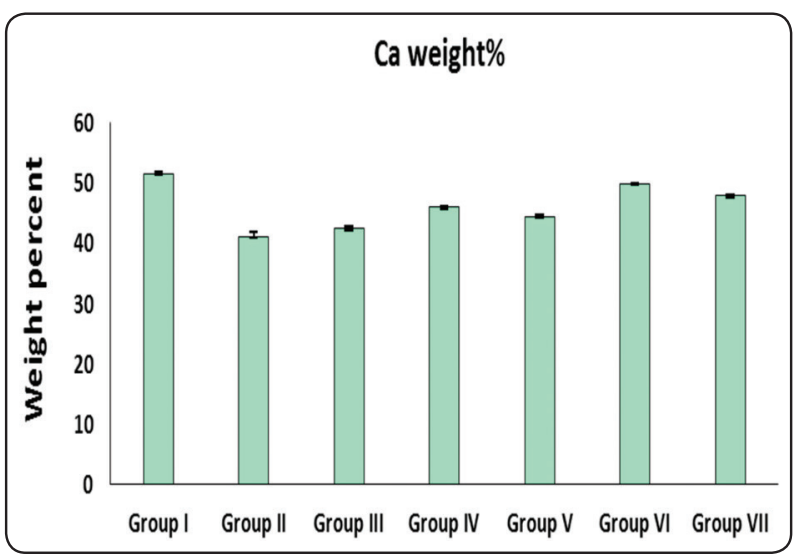

Fig. 9: Bar chart representing $\mathrm{Ca}$ weight percent in all groups. Data were expressed as Mean $\pm S D$, $p$ value $<0.05$ was significant group V compared to group IV ( $p$ value $=0.004)$ as well as in group VII when compared to group VI ( $p$ value $=0.005)$ (Table 2 and figs. 11\&12).

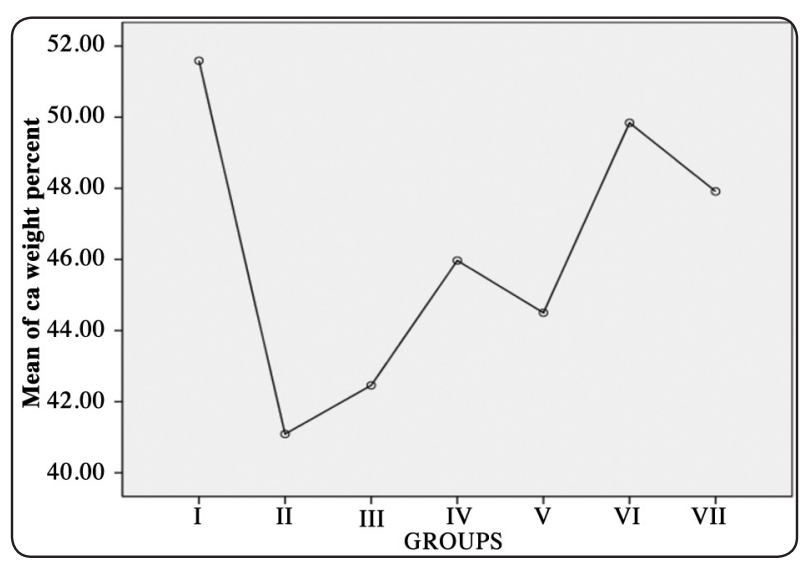

Fig. 10: Line chart representing the mean of Ca weight percent between groups

TABLE (2) Showing mean and standard deviation values of $\mathrm{P} w \mathrm{wt}$ for all groups (I-VII)

\begin{tabular}{|l|c|c|c|c|c|}
\hline \multicolumn{1}{|c|}{ Group } & Mean & Standard Deviation & Minimum & Maximum & P value \\
\hline Group I & $\mathbf{2 1 . 3 9}$ & 0.12 & 21.27 & 21.51 & \\
\hline Group II & $\mathbf{1 7 . 1 4}$ & 0.16 & 16.98 & 17.30 & \\
\hline Group III & $\mathbf{1 7 . 8 2}$ & 0.075 & 17.75 & 17.90 & \multirow{2}{*}{$<0.001$} \\
\hline Group IV & $\mathbf{1 9 . 1 6}$ & 0.14 & 19.02 & 19.30 & \\
\hline Group V & $\mathbf{1 8 . 6 6}$ & 0.14 & 18.52 & 18.80 \\
\hline Group VI & $\mathbf{2 0 . 2 7}$ & 0.17 & 20.10 & 20.44 & \\
\hline Group VII & $\mathbf{1 9 . 7 8}$ & 0.035 & 19.75 & 19.82 & \\
\hline
\end{tabular}




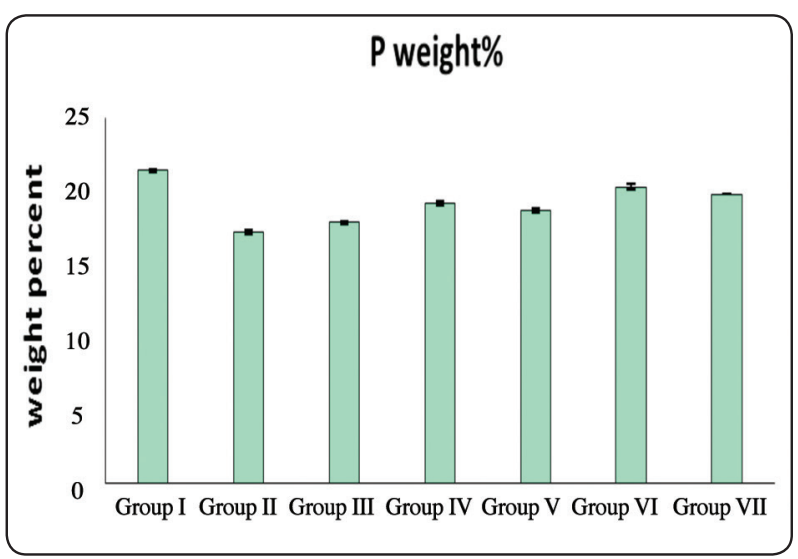

Fig. 11: Bar chart showing $P$ weight percent in all groups.

Data were expressed as Mean $\pm S D$, $p$ value $<0.05$ was significant

\section{DISCUSSION}

Enamel is the chief targeted tissue in the process of erosion and its destruction may have multiple etiological factors ${ }^{(4)}$. This in vitro research demonstrated the demineralizing effect of two commercially available energy drinks (EDs) on enamel of human dentition. It has been found that only few studies have discussed the effect of EDs on enamel erosion ${ }^{(\mathbf{1 0})}$.

Our study was carried out on the cervical third of enamel which is the most affected area of the tooth. This was confirmed by Takahashi et al, $2008^{(25)}$ who reported decreased calcification of the cervical area of human teeth with significant reduction of calcium $(\mathrm{Ca})$ and phosphorous $(\mathrm{P})$ contents more than other parts of enamel.

It is well known that saliva has a remineralizing effect as it is supersaturated with $\mathrm{Ca}$ and $\mathrm{P}$, which may affect the progression of erosive process ${ }^{(26)}$. Thus, artificial saliva was not used as a control medium in our study which may change the outcome of the results. Another opinion believe that despite the existence of saliva in in situ experiments, the reported data are the same for both in vivo and in vitro methods, which recommends the use of in vitro model for simplicity ${ }^{(11)}$.

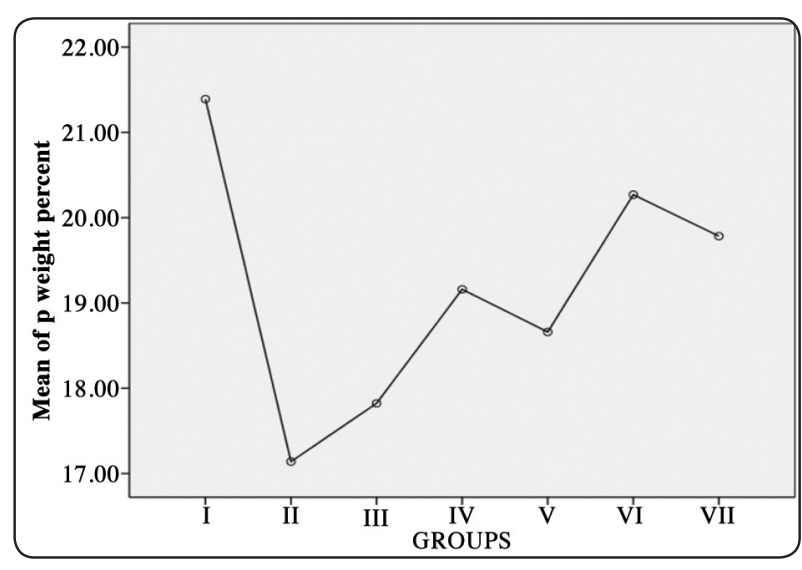

Fig. 12: Line chart representing the mean of $P$ weight percent between groups

Scanning electron microscopic results of this work revealed several surface defects in groups II and III (Power Horse and Cornelius groups) including cracks, porosities, pits and erosion of varying degrees of intensities. These data are in accordance with Jeong et al, $2014{ }^{(27)}$ who noticed rough surface demineralized enamel due to erosion, together with cracks between the hydroxyapatite crystals in SEM results of teeth immersed in ED 'Burn Intense'. Moreover, anterior teeth immersed in sports drink 'Sting' showed surface pitting and irregularities with areas of structural loss of enamel ${ }^{(28)}$. Also, EDs 'Gatorade' and 'Red Bull' exhibited high erosive potential on human dental enamel respectively ${ }^{(11,29)}$. Another study demonstrated decreased surface micro-hardness of enamel after submersion in EDs ${ }^{\left({ }^{(30)}\right.}$. Enamel hardness reduction is the primary evidence of erosion, which is a main sign of the action of erosive drinks in short periods ${ }^{(\mathbf{1 0})}$.

Meanwhile, surface erosion in this experiment was found to be more aggressive in Power Horse group (II) when compared to Cornelius group (III). In group III, the surface texture was maintained when compared to the control one, and the morphological defects were of less intensity with well defined pattern of perikymata. In this regard, some authors returned the erosive effect of ED to their $\mathrm{pH}$ 
value, which reflects the dissociated hydrogen ion concentration. It is supposed that erosion occurs when the $\mathrm{pH}$ of the solution is lesser than the critical $\mathrm{pH}$ of hydroxyapatite, which is $5.5^{(2)}$. At low $\mathrm{pH}$, hydrogen ions dissolve the minerals leading to diffusion of $\mathrm{Ca}$ and $\mathrm{P}$ out of the tooth ${ }^{(31,32)}$. Our results revealed that the $\mathrm{pH}$ value of Power Horse drink is 2.52, while Cornelius is higher reaching a value of 2.75 , thus explaining the more intense erosive effect of Power Horse drink over Cornelius.

On the other hand, it has been recently accepted that the titratable acidity (TA) is more indicative for the erosive capacity of the solution rather than the actual $\mathrm{pH}$ value. TA is the amount of alkali needed to neutralize an acidic solution, that is, the erosive potential of the beverage ${ }^{(33,34)}$. This means that increased TA of the solution results in more erosive effect ${ }^{(1)}$. In the herein study, our findings come in agreement with these data, as the measured TA of Power Horse drink and Cornelius was found to be 26.8 and 19.4 respectively; demonstrating higher enamel surface erosion of Power Horse beverage. This forgoing observation was coincident with Matumoto et al, 2018 ${ }^{(\mathbf{1 0})}$ who detected significant decrease in micro-hardness of teeth soaked in 'Red Bull' ED which has low $\mathrm{pH}$ and high TA; being very difficult to be neutralized.

Similar to other soft drinks, EDs also contain citric acid and/or citrates in their composition which are added as a flavoring agent ${ }^{(2)}$. Citric acid is a highly aggressive acid promoting tooth demineralization $^{(5)}$. It is a tribasic carboxylic acid which binds with hydroxyapatite crystals leading to dissolution of enamel. Citrate ions chelates $\mathrm{Ca}$ and $\mathrm{P}$ ions forming a soluble complex, enhancing further demineralization ${ }^{(35)}$ thus causing elevated TA levels ${ }^{(29)}$.

Moreover, frequency and time of exposure to acidic solution have great influence on enamel erosion ${ }^{(6)}$. In the ongoing experiment, premolars were immersed in ED for 10 days interval and changed daily. It has been reported that prolonged submersion and contact between the tooth surface and the acidic solution promotes increased chances for erosion to occur. Hence, EDs can cause massive enamel destruction if they were inadequately and repeatedly consumed ${ }^{(\mathbf{1})}$. Confirming our results, Owens et al, 2014 ${ }^{(9)}$ exposed human teeth to 'Red Bull' ED for 10 days duration. The authors recognized high percent weight loss of enamel samples indicating enamel dissolution and erosion. Furthermore, SEM revealed that increase exposure of enamel specimens to acidic drinks ends with severe surface erosion and cracks ${ }^{(1)}$.

In the oral environment, demineralization and remineralization cycles are continuous. Early stages of demineralization are reversible through remineralization process where $\mathrm{Ca}$ and $\mathrm{P}$ ions are allowed to diffuse into the lesion restoring the lost tooth structure ${ }^{(12)}$. In this work, we aimed to demonstrate the effect of milk as a remineralizing agent after immersion in different types of EDs. This is supported by instructions given to individuals to consume milk immediately after having meals or acidic drinks, which prevents demineralization and limits progression of dental erosion ${ }^{(36,13,37)}$.

In milk groups (groups IV-VII), milk was replaced every 2 hours throughout the experiment which is the safe period before its deterioration. It has been documented that it is safe to keep foodstuff at room temperature for maximum 2 hours ${ }^{(38)}$.

SEM results revealed better remineralizing effect in groups IV and VI (lactose free treated) rather than those treated with almond milk (groups $\mathrm{V}$ and VII). Calcific deposits of various patterns were haphazardly distributed filling all cracks and surface defects. This finding was parallel to that reported by Chung et al, 2013 and Vieira et al, $20188^{(39,37)}$. The authors proved that lactose free milk significantly raised enamel micro-hardness when compared to almond milk following treatment with Coca-Cola, suggesting remineralization of eroded enamel. Grenby et al, $2001{ }^{(40)}$ explained that elimination of lactose did not reduce the remineralizing potential 
of milk against demineralization induced by acidic solutions. This means that lactose free milk has the same protective and remineralizing effect of whole bovine milk. Moreover, another study used enamel and dentin slabs to grow Streptococcus mutans biofilms, and then exposed to different types of milk. Lactose-free milk was able to keep the $\mathrm{pH}$ above the demineralization level causing least structural loss of enamel and dentin ${ }^{(41)}$.

$\mathrm{Ca}, \mathrm{P}$ ions and casein; particularly casein phosphopeptide amorphous calcium phosphate complexes (CPP-ACP) are the main constituents of bovine milk. They are mostly responsible for the remineralizing and protective effects on teeth. CPP$\mathrm{ACP}$ can bind to $\mathrm{Ca}$ and $\mathrm{P}$ in solutions and to tooth surface. This keeps $\mathrm{Ca}$ and $\mathrm{P}$ ions in amorphous state enhancing them to diffuse within the tooth enamel ${ }^{(42,12)}$. In addition, deposition of minerals and organic content on enamel forms a protective layer, thus decreasing the dissolution of hydroxyapatite crystals and preventing ions discharge ${ }^{(36)}$.

EDX analysis is considered the most relevant experimental method to identify the amount of certain elements within the enamel. It is based on the analysis of the weight percent of a definite constituent in enamel in few cubic microns, and then relates their distribution to the histological features of enamel ${ }^{(43)}$.

EDX results presented statistically significant decrease in $\mathrm{Ca}$ and $\mathrm{P}$ weight percent in group II compared to group III as a result of increased destruction of hydroxyapatite crystals caused by Power Horse ED. These data were confirmed by the SEM showing more aggressive effect of Power Horse ED over Cornelius.

Moreover, statistically significant increase in $\mathrm{Ca}$ and $\mathrm{P}$ weight percent in group IV in relation to group $\mathrm{V}$ and similarly, statistically significant increase in group VI compared to group VII were also detected. These obtained results reflect the highly mineralizing effect of lactose free milk over almond; which was confirmed by increased calcific deposits filling all cracks and defects in lactose free group.

Nevertheless, SEM results revealed that the degree of mineralization was of less intensity in groups VI and VII in relation to groups IV and V. This could be attributed to the previous SEM results which demonstrated less demineralizing effect of Cornelius ED in relation to Power Horse ED. Therefore, groups VI and VII revealed minimal calcific deposits and crystals in an attempt to present best remineralizing effect and restore the surface architecture.

From the fore mentioned data; we can conclude that the consumption of EDs produces erosive defects of varying intensity on the enamel surface of human teeth. Thus, reducing the frequency of exposure of teeth to acidic beverages along with reduction of oral residence time are the most effective methods to minimize dental erosion hazards. Also, the intake of remineralizing agents; such as milk, immediately following every meal containing acidic diet is mandatory.

\section{REFERENCES}

1- Enam, F., Mursalat, M., Guha, U., Aich, N., Anik, M., Nisha, N., Esha, A. and Khan, M.: Dental erosion potential of beverages and bottled drinking water in Bangladesh. International Journal of Food Properties. 20: 2499-2510, 2017.

2- Kaur, M., Bhaskar, V., Ganesh, M., Joshi, K. and Trivedi, $\mathrm{K}$.: Comparative evaluation of the erosive potential of commonly used beverages and medicated syrup- an in vitro study. The Journal of Ahmedabad Dental College and Hospital. 3, 19-25, 2012.

3- Mathew, S., Luke, A., Walia, T., Masri, A., Jamal, H. and Pawar, A.: Effect of Fruit Juices and Other Beverages on Loss of Tooth Structure. Pesq. Bras. Odontoped. Clin. Integr., 18: e3888, 2018.

4- Melo, M., Passos, V., Lima, J., Santiago, S. and Rodrigues, L.: Carbohydrate-electrolyte drinks exhibit risks for human enamel surface loss. Restorative Dentistry and Endodontics. 41: 246-254, 2016.

5- Hossain, M., Jahan, I., Shawan, M., Parvin, A., Hasan, M., Uddin, K., Akter, S., Banik, S., Hasan, A., Morshed, 
M., Rahman, N. and Rahman, B.: Determination of $\mathrm{pH}$, caffeine and reducing sugar in energy drinks available in Bangladesh. New York Science Journal. 8: 92-96, 2015.

6- Latti, B. and Kalburge, J.: Sports drinks and its effect on teeth. International Journal of Information Research and Review. 2: 805-807, 2015.

7- Lara, B., Gonzalez-Millán, C., Salinero, J., Abian-Vicen, J., Areces, F., Barbero-Alvarez, J., Munoz, V., Portillo, L., Gonzalez-Rave, J. and Del Coso, J.: Caffeine-containing energy drink improves physical performance in female soccer players. Amino Acids. 46:1385-92, 2014.

8- Erdemir, U., Yildiz, E., Saygi, G., Altay, N., Eren, M. and Yucel, T.: Effects of energy and sports drinks on tooth structures and restorative materials. World Journal of Stomatology. 5: 1-7, 2016.

9- Owens, B., Mallette, J. and Phebus, J.: Effects of Carbonated Cola Beverages, Sports and Energy Drinks and Orange Juice on Primary and Permanent Enamel Dissolution. Austin J. Dent., 1: id1004, 2014.

10- Matumoto, M., Terada, R., Higashi, D., Fujimaki, M., Suga, S. and Guedes-Pinto, A.: In vitro effect of energy drinks on human enamel surface. Rev. Odontol. UNESP., 47: 57-62, 2018.

11- Yamamoto, E., Vanderlei, A., Amaral, R., Di Nicoló, R., Rocha, J. and Araújo, M.: Influence of three types of drinks on the surface of human dental enamel: in vitro study. Rev. Gaúcha. Odontol., 61: 41-46, 2013.

12- Vakil, I., Shetty, V. and Hegde, A.: Remineralizing and anticariogenic benefits of pure milk- A review. NUJHS., 6: 57-62, 2016.

13- Sinaga, Y.: The Increase Of Tooth Enamel Hardness Score After Cow Milk Immersion Compared To Artificial Saliva On Demineralized Tooth. IOSR Journal of Dental and Medical Sciences. 16: 6-10, 2017.

14- Perotti, M., Veronica, W., Venica, C. and Viviana, B.: Dairy Products Modified in their Lactose Content. Current Nutrition \& Food Science. 8: 8-18, 2012.

15- Ellis, D. and Lieb, J.: Hyperoxaluria and genitourinary disorders in children ingesting almond milk products. The Journal of Pediatrics. 167: 1155-1158, 2015.

16- Sethi, S., Tyagi, S. and Anurag, R.: Plant-based milk alternatives an emerging segment of functional beverages: a review. J. Food Sci. Technol., 53: 3408-3423, 2016.
17- Widanti, H., Herda, E. and Damiyanti, M.: Effect of cow and soy milk on enamel hardness of immersed teeth. J. Phys.,: Conf. Ser. 884 012006, 2017.

18- Kant, R. and Broadway, A.: The Benefits of Consuming Soya Milk- A Review. Trends in Biosciences. 8: 1159$1162,2015$.

19- Lee, J., Townsend,J., Thompson, T., Garitty, T., De, A., Yu, Q., Peters, B. and Wen, Z. Analysis of the Cariogenic Potential of Various Almond Milk Beverages Using Streptococcus mutans Biofilm Model In Vitro. Caries Res., 52: 51-57, 2018.

20- Yetunde, A. and Ukpong, U.: Nutritional and Sensory Properties of Almond (Prunus amygdalu Var. Dulcis) Seed Milk. World Journal of Dairy \& Food Sciences. 10: 117$121,2015$.

21- Wang, V. America's almond milk boom tops $\$ 700$ million in sales. 2016. Accessed nov. 26, $2016 \mathrm{Http}: / / w w w$. Bloomberg.Com/news/articles/2014-08-08/the-almondmilk-boom-silks-huge-saleslead-the-way-trounce-soys (archived by website@ at http://www.Webcitation. Org/6mlvwuvep)

22- Amoras, D., Corona, S., Rodrigues, A. and Serra, M.: Effect of Beverages on Bovine Dental Enamel Subjected to Erosive Challenge with Hydrochloric Acid. Braz. Dent. J., 23: 367-372, 2012.

23- McDougall, W.: Effect of milk on enamel demineralization and remineralization in vitro. Caries Res., 11: 166-72, 1977.

24- Chan, Y.: Biostatistics 102: Quantitative Data - Parametric \& Non-parametric Tests. Singapore Med. J., 44: 391-396, 2003.

25- Takahashi, M., Goto, S., Mori, K. and Mataga, I.: Difference of histology and elemental composition of cervical enamels among human permanent teeth. Front. Master Sci. China. 2: 437-40, 2008.

26- Buzalaf, M., Hannas, A. and Kato, M.: Saliva and dental erosion. J. Appl. Oral Sci., 20: 493-502, 2012.

27- Jeong, M., Jeong, S., Son, J., Chung, S., Kim, A., Kang, E., Kim, E., Kim, H., Jang, K., Cho, M., Cheon Y., Choi, H. and Lim, D.: A Study on the Enamel Erosion Caused by Energy Drinks. J. Dent. Hyg. Sci., 14: 597-609, 2014.

28- Kazmi, S., Mughal, A., Habib, M., Ayaz, M., Tariq, H., and Khan, A. Effects on the enamel due to the carbonated drinks - A SEM study. Pakistan Oral and Dental Journal. 36, 221- 225, 2016. 
29- Trivedi, K., Bhaskar, V., Ganesh, M., Venkataraghavan, K., Choudhary, P., Shah, S., and Krishnan, R.: Erosive potential of commonly used beverages, medicated syrup, and their effects on dental enamel with and without restoration: An in vitro study. Journal of Pharmacy and Bioallied Sciences. 7: S474-80, 2015.

30- Han-Na, O. and Hye-Jin, L.: The Effect of Energy Drink on Enamel Erosion. Journal of dental hygiene science. 15: 419-423, 2015

31- Kim, M., Jeon, J., Park, H., Bae, C., Park, J., Bae, S. and Bae, M.: Effect of Energy Drinks on the Dental Enamel Erosion and Mouse Teeth Growth. Korean Society for Biotechnology and Bioengineering Journal. 29: 112-117, 2014.

32- Adhani, R., Sukmana, B. and Suhartono, E. Effect pH on demineralization dental erosion. International Journal of Chemical Engineering and Applications. 6: 138-141, 2015.

33- Tenuta, L., Fernández, C., Brandão, A. and Cury, J.: Titratable acidity of beverages influences salivary $\mathrm{pH}$ recovery. Braz. Oral Res., 29:1-6, 2015.

34- Oh, S., Perinpanayagam, H., Lee, Y., Kum, J., Yoo, Y., Lim, S., Chang, S., Shon, W., Lee, W., Baek, S. and Kum, $\mathrm{K}$. : Effect of acidic solutions on the microhardness of dentin and set Ortho MTA and their cytotoxicity on murine macrophage. Restor. Dent. Endod., 41:12-21, 2016.

35- Jensdottir, T., Holbrook, P., Nauntofle, B., Buchwald, C. and Bardow, A.: Immediate erosive potential of cola drinks and orange juices. J. Dent. Res., 85: 226-230, 2006.
36- Lachowski, K., Ferreira, D., Oliveira, T. and Sobral, M.: Effect of the Mixture of Coffee or Chocolate to Milk in the Progression of Des-Remineralization of Tooth Enamel - An in Vitro Study. Brazilian Research in Pediatric Dentistry and Integrated Clinic. 14:183-190, 2014.

37- Vieira, A., Chung, C., Raffensperger, S. and Muluk, P.: Milk Reverts the Effects of an Enamel Erosive but Healthy Diet. Pesq. Bras. Odontoped. Clin. Integr., 18:e3848, 2018.

38- NSW Food Authoroty. 4 hour- 2 hour. www.foodauthoroty. nsw.gov.au/_.../4_hour_2_hour.pdf, 2015.

39- Chung, C., Raffensperger, S. and Vieira, A.: Milk Have Positive Effects Comparable to Fluoride on Enamel. Conference: Conference: IADR/AADR/CADR General Session and Exhibition March 2013.

40- Grenby, T., Andrews, A., Mistry, M. and Williams, R.: Dental caries-protective agents in milk and milk products: investigations in vitro. J. Dent., 29: 83-92, 2001.

41- Giacaman, R. and Munoz-Sandoval, C: Cariogenicity of different commercially available bovine milk types in a biofilm caries model. Pediatr. Dent., 36: 1E-6E, 2014.

42- Kalra, D., Kalra, R., Kini, P. and Prabhu, C.: Nonfluoride Remineralization: An Evidence-Based Review of Contemporary Technologies. Journal of Dental and Allied Sciences. 3: 24-33, 2014.

43- Samuel, S. and Rubinstein, C.: Microhardness of enamel restored with fluoride and non-fluoride releasing dental materials. Braz. Dent. J., 12: 35-8, 2001. 